\title{
BMJ Open Fetal umbilical artery Doppler pulsatility index and childhood neurocognitive outcome at 12 years
}

\author{
Fionnuala Mone, ${ }^{1,2}$ Barbara McConnell, ${ }^{3}$ Andrew Thompson, ${ }^{4}$ Ricardo Segurado, ${ }^{5}$ \\ Peter Hepper, ${ }^{6}$ Moira C Stewart, ${ }^{4}$ James C Dornan, ${ }^{7}$ Stephen Ong, ${ }^{7}$ \\ Fionnuala M McAuliffe, ${ }^{1,2}$ Michael D Shields ${ }^{4,8}$
}

To cite: Mone $\mathrm{F}$, McConnell B, Thompson A, et al. Fetal umbilical artery Doppler pulsatility index and childhood neurocognitive outcome at 12 years. BMJ Open 2016;6:e008916. doi:10.1136/bmjopen-2015008916

- Prepublication history and additional material is available. To view please visit the journal (http://dx.doi.org/ 10.1136/bmjopen-2015008916).

Received 27 May 2015 Revised 27 April 2016 Accepted 3 May 2016

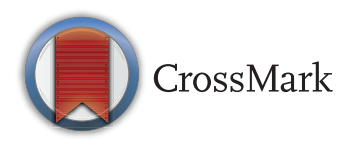

For numbered affiliations see end of article.

Correspondence to Professor Michael D Shields; m.shields@qub.ac.uk

\section{ABSTRACT}

Objective: To determine whether an elevated fetal umbilical artery Doppler (UAD) pulsatility index (PI) at 28 weeks' gestation, in the absence of fetal growth restriction (FGR) and prematurity, is associated with adverse neurocognitive outcome in children aged 12 years.

Methods: Prospective cohort study, comparing children with a normal fetal UAD PI ( $<90$ th centile) $(n=110)$ and those with an elevated $\mathrm{PI}$ ( $\geq 90$ th centile) $(n=40)$. UAD was performed at 28,32 and 34 weeks gestation. At 12 years of age, all children were assessed under standardised conditions at Queen's University, Belfast, UK to determine cognitive and behavioural outcomes using the British Ability Score-II and Achenbach Child Behavioural Checklist Parent Rated Version under standardised conditions. Regression analysis was performed, controlling for confounders such as gender, socioeconomic status and age at assessment.

Results: The mean age of follow-up was 12.4 years $( \pm 0.5 \mathrm{SD})$ with $44 \%$ of children male $(n=63)$. When UAD was assessed at 28 weeks, the elevated fetal UAD group had lower scores in cognitive assessments of information processing and memory. Parameters included (1) recall of objects immediate verbal $(p=0.002)$, (2) delayed verbal $(p=0.008)$ and (3) recall of objects immediate spatial $(p=0.0016)$. There were no significant differences between the Doppler groups at 32 or 34 weeks' gestation.

Conclusions: An elevated UAD PI at 28 weeks' gestation in the absence of FGR or prematurity is associated with lower scores of declarative memory in children aged 12 years. A potential explanation for this is an element of placental insufficiency in the presence of the appropriately grown fetus, which affects the development of the fetal hippocampus and information processing and memory long-term. These findings, however, had no impact on overall academic ability, mental processing and reasoning or overall behavioural function.

\section{INTRODUCTION}

The association between fetal growth in utero and disease in later life was first proposed by

\section{Strengths and limitations of this study}

Novel in concept/design.

- Longest follow-up in a group of children with abnormal in utero UAD measurements.

- Validity of methodology-standard investigation/ same investigator that is blinded

- Two rounds of recruitment in order to obtain adequate numbers led to uneven numbers in both groups.

- Lack of placental and estimated fetal weight data.

Barker in the 1990s and is supported by further studies over past decades. ${ }^{1-4}$ The fetal umbilical artery Doppler (UAD) pulsatility index (PI) measurement serves as a surrogate marker for the well-being of the fetus in utero through assessing impedance within the fetoplacental circulation and is an indirect measure of resistance to flow within the placental vasculature. Typically, the PI is assessed using insonation of the fetal umbilical artery using pulsed-wave colour Doppler ultrasonography and subsequent analysis can be performed to obtain gestation-dependent centiles for the PI, with a PI of greater than the 90th or 95th centile signalling increased level of impedance in the majority of cases. ${ }^{5}$

While an abnormal UAD measurement is associated with perinatal death, its relationship with neurodevelopmental outcome is less clear. A recent Cochrane review of the application of the UAD concluded that there was no available evidence to assess the ability to predict substantive long-term outcomes, including neurodevelopment. ${ }^{6}$ In the presence of fetal growth restriction (FGR), an abnormal Doppler has an association with abnormal childhood neurodevelopment. ${ }^{7}$ An association between an abnormal UAD and neurological outcome in the apparently normally grown fetus has not been described to date.

The primary objective of this study was to compare childhood neurodevelopmental 
outcome in terms of (1) cognitive and (2) behavioural performance in children at the age of 11-12 years who had elevated fetal UAD PI at 28 weeks' gestation compared to a control group with normal measurements, in the absence of FGR and preterm delivery.

\section{PATIENTS AND METHODS}

In 1988, a prospective cohort study of 2097 consecutive non-growth-restricted singleton pregnancies underwent serial UAD PI testing at 28, 34 and 38 weeks' gestation to assess whether the UAD PI could predict peri-natal outcome data (RB Beattie. Evaluation of umbilical artery Doppler ultrasound in human pregnancy. [Unpublished Thesis]. [Belfast (UK)]: Queen's University, Belfast; 1988).

\section{Patient selection}

The present study population included a nested casecontrol subset of patients from the aforementioned study aged 11-12 years (RB Beattie, Unpublished Thesis, 1988) that had had an in utero UAD PI, randomly selected either above (abnormal) or below (normal) the 90 th centile for gestational age at 28 weeks' gestation as per the pre-defined criteria, ${ }^{8}$ and alternatively defined as abnormal or normal on the PI centile at 34 and 38 weeks of gestation. ${ }^{9}$ A power calculation estimated that 100 subjects per group should be tested to detect a mean difference of 7.5 (SD of 15) in the scores for components of the British Ability Score-II (BAS-II) assessments of cognitive function at 28 weeks, with a power of $94 \%$ at a significance level of 0.05 . In the course of the study, low response rates limited the sample to 180 with a 1:3.5 imbalance; however, a post hoc calculation indicated power was maintained at $79 \%$. Results and assessments centred around UAD PI at 28 weeks due to the known association between Doppler status from 27 weeks and neurodevelopmental delay in pregnancies affected by FGR, high-lighting the significance of assessing at this gestation. ${ }^{10}$ Anticipating the difficulties in locating and recruiting participants for follow-up research, 724 names were initially selected and traced through the Central Services Agency. Following two rounds of recruitment, 204 subjects underwent psychological assessment. Subjects delivered pre-term ( $<37$ weeks), with a small-for-gestational-age birth weight $(<10$ th centile) or identifiable genetic syndromes, were subsequently omitted, leaving an overall sample of 180 subjects. Following ethical approval from the Northern

Table 1 Demographic characteristics of study cohort at 28 weeks' gestation in the normal ( $<90$ th centile) and elevated ( $>90$ th centile) umbilical artery Doppler (UAD) pulsatility index (PI) reported as mean with SDs (SD) or percentages, respectively

\begin{tabular}{|c|c|c|c|}
\hline & $\begin{array}{l}\text { UAD } \mathrm{Pl}<90 \text { th centile } \\
\mathrm{N}=140\end{array}$ & $\begin{array}{l}\text { UAD PI>90th centile } \\
\mathrm{N}=40\end{array}$ & $\begin{array}{l}\text { All individuals } \\
\mathrm{N}=180\end{array}$ \\
\hline Gender (male) & $36(54 \%)$ & 27 (44\%) & $63(49 \%)$ \\
\hline Age of child (years) & $12.4(0.5)$ & $12.4(0.4)$ & $12.4(0.5)$ \\
\hline Age of mother (years) & $40.5(5.3)$ & $39.9(5.8)$ & $40.2(5.6)$ \\
\hline Weight (kg) & 44.1 (10.3) & $45.5(11.7)$ & $44.9(11.1)$ \\
\hline Height $(\mathrm{cm})$ & $151.6(7.7)$ & $151.0(7.6)$ & $151.3(7.6)$ \\
\hline Townsend score & $1.66(3.44)$ & $1.66(3.45)$ & $1.66(3.4)$ \\
\hline \multicolumn{4}{|l|}{ Tanner public hair staging } \\
\hline 1 & 32 (49\%) & $29(48 \%)$ & $61(48 \%)$ \\
\hline 2 & $15(23 \%)$ & $15(25 \%)$ & $30(24 \%)$ \\
\hline 3 & $5(8 \%)$ & $8(13 \%)$ & $13(10 \%)$ \\
\hline 4 & $13(20 \%)$ & $7(12 \%)$ & $20(16 \%)$ \\
\hline 5 & $1(2 \%)$ & $1(2 \%)$ & $2(2 \%)$ \\
\hline $11+$ grade=pass & $39(59 \%)$ & $42(69 \%)$ & $81(64 \%)$ \\
\hline Maternal smoking & $44(33 \%)$ & 15 (37\%) & 59 (34\%) \\
\hline \multicolumn{4}{|l|}{ Mode of delivery } \\
\hline Normal (SVD) & $112(81 \%)$ & $31(76 \%)$ & $143(79 \%)$ \\
\hline Assisted breech & $1(1 \%)$ & $1(2 \%)$ & $2(1 \%)$ \\
\hline Instrumental & $15(11 \%)$ & $3(7 \%)$ & $18(10 \%)$ \\
\hline Caesarean section & $11(8 \%)$ & $6(15 \%)$ & $17(9 \%)$ \\
\hline Birth weight $(\mathrm{g})$ & 3679 (586) & $3429(426)$ & $3532(511)$ \\
\hline Gestation (weeks+days) & $40+3(1+0)$ & $40+1(1+0)$ & $40+2(1+0)$ \\
\hline APGAR $1 \mathrm{~min}$ & $8(7,9)$ & $8(7,9)$ & $8(7,9)$ \\
\hline APGAR 5 min & $9(9,9)$ & $9(9,9)$ & $9(9,9)$ \\
\hline Cord pH & $7.29(0.14)$ & 7.30 (0.09) & $7.29(0.11)$ \\
\hline PI 28 weeks & $0.95(0.06)$ & $1.69(0.29)$ & $1.34(0.43)$ \\
\hline PI 34 weeks & $0.96(0.19)$ & $1.06(0.20)$ & $1.02(0.20)$ \\
\hline PI 38 weeks & $0.90(0.20)$ & $1.03(0.15)$ & $0.97(0.18)$ \\
\hline
\end{tabular}


Ireland Research and Ethics committee, Queen's University Belfast, informed consent was obtained from parents and children for this study.

\section{Assessments}

In addition to physical assessment of cardiovascular and respiratory status, ${ }^{4}$ cognition and behaviour were tested under standardised conditions using validated questionnaires by a single child psychologist who was blinded to UAD PI category. Cognitive function was assessed using the BAS-II questionnaire, ${ }^{11}$ which is inclusive of (1) diagnostic scales; assessing information processing and memory, (2) achievement scales; assessing academic performance and (3) core scales which formulate the global conceptual ability score (GCA); assessing mental processing and reasoning. Behavioural function was assessed by a parent questionnaire through the Achenbach Child Behavioural Checklist Parent Rated Version (CBCL), ${ }^{12}$ which rates the presence of specific behaviours on a 3-point rating scale.

\section{Statistical analysis}

Number and percentages were derived for categorical characteristics, and means, SDs and medians and first and third quartiles (IQR) were calculated for continuous characteristics. Categorical characteristics were compared between the UAD PI groups using Student's t-test after weighting for non-response. Several of the demographic and psychometric measures had a skew or other non-normal distribution, and therefore the nonparametric Mann-Whitney tests were performed to compare the normal and elevated UAD PI groups. Outcomes of interest were carried forward to compare the normal and elevated UAD PI groups while adjusting for potential confounders including gender, age at assessment and Townsend score as a proxy for socioeconomic status. These outcomes included all variables, which showed statistical significance at an $\alpha$ of 0.1 from the Mann-Whitney tests. Linear regression analyses were performed to adjust for confounders, and residuals closely inspected to verify assumptions were met. No correction for multiple testing was performed, and a $\mathrm{p}$ value threshold of 0.05 was considered statistically significant in the final adjusted analyses. Psychometric scores with extreme non-normal distributions were modelled using binary logistic regression after dichotomisation at the median and adjusted for the same confounders. All analyses were performed using IBM SPSS V.20, and weighted by the non-response rates in the respective recruitment cohorts and high/normal PI strata.

\section{RESULTS}

This study included 180 subjects; 40 with a UAD PI of $\geq 90$ th centile (elevated) and 140 with a UAD PI of $<90$ th centile (normal). This accounts for $19.0 \%$ (40/ $210)$ and $7.4 \%(140 / 1887)$ of the original 2087 cohort,

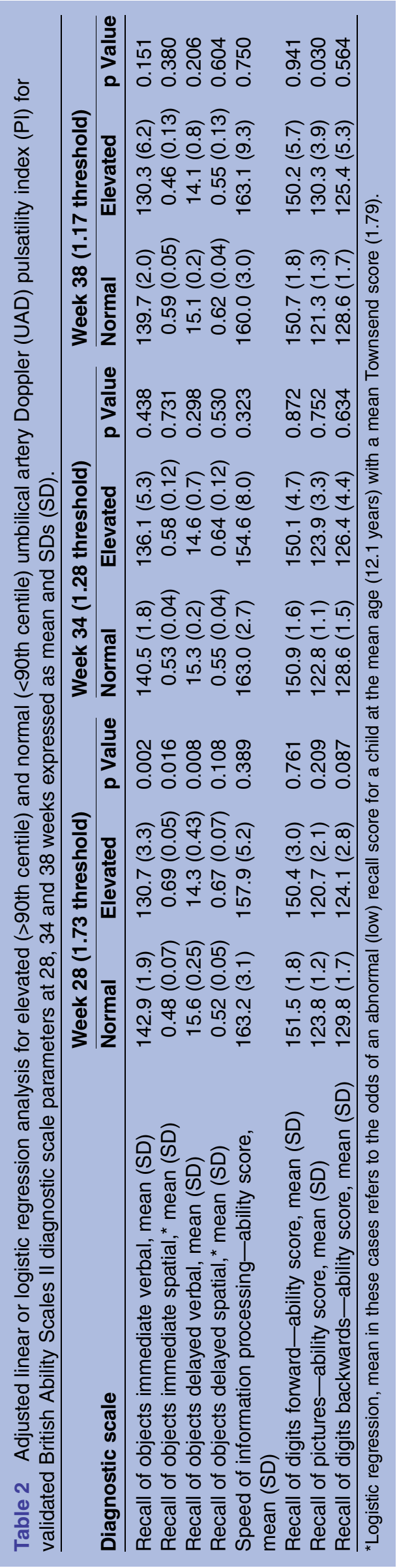


respectively. The demographics of the study population at the time of assessment, delivery and during gestation are demonstrated in table 1.

Following adjustment for potential confounders including gender, age at assessment and Townsend score, the findings between UAD PI groups (normal and elevated) were compared (tables 2-5). These findings are demonstrated for the variable aforementioned psychometric parameters assessed inclusive of the BAS II diagnostic scales (table 2), achievement scales (table 3), core scales (table 4) and Achenbach CBCL (table 5) for UAD performed at 28, 34 and 38 weeks, respectively, with associated $p$ values. The unadjusted version of this analysis is provided in online supplementary file 1 .

Scores of processing and memory; notably recall of objects immediate verbal, immediate spatial and delayed verbal in the diagnostic scale group were significantly lower in the elevated UAD PI group ( $p=0.002,0.016$ and 0.008 , respectively). This did not appear to be the case when UAD was measured in groups at later gestations. There were no significant differences between UAD PI groups in the achievement scales group, and in the GCA group, the overall GCA score was not significantly different between groups. In terms of the Achenbach child behaviour checklist parent-rated version (CBLC), internalising and externalising parameters were not overall significantly different.

\section{DISCUSSION}

This study demonstrates that at 12 years of age, in the absence of FGR and prematurity, an elevated fetal UAD PI at 28 weeks' gestation is associated with significantly lower scores in parameters of cognitive function in the form of information processing and memory. There is no association between abnormal fetal UAD PI and overall academic ability, mental processing and reasoning or overall behavioural function of children at this age.

Existing research suggests that in FGR, the degree of neurodevelopmental abnormality in childhood is proportionally related to the impedance within the UAD. ${ }^{7}$ Early-onset FGR is associated with impaired placental perfusion due to a reduction in the overall crosssectional villous vascular area, which appears to affect UAD resistance when villous damage is $>30 \% .{ }^{13}$ Our study agrees with existing research which demonstrates that there is an effect of abnormal UAD measurement in the coexistence of FGR in terms of impaired childhood neurodevelopment, ${ }^{714}$ yet our study is unique in assessing neurodevelopmental outcomes in children with abnormal UAD, but no associated FGR or prematurity. One explanation may lie in the definition of FGR; a topic much debated within the literature. Traditional definitions of FGR, that is, birth weights $<10$ th and $<3 \mathrm{rd}$ centile for gestational age which were used at the time of the original study, are being replaced by histological placental evidence of impaired perfusion or 'placental disease'. Emerging studies demonstrate abnormal cerebral and placental blood flow distributions within appropriately grown fetuses as a marker of placental insufficiency and call for a revision of the diagnosis of fetuses 'failing to reach their growth potential'. ${ }^{15}$

The strength of this study is that the cohort is that it is the first of its' kind to assess the impact of an abnormal fetal UAD PI in a non-growth restricted population on long-term neurodevelopmental outcome. In addition, this study represents the longest follow-up in a group of children with abnormal in utero UAD measurements. ${ }^{7}$ A recent study, which is the longest cohort study to date of extreme low-birth weight survivors, demonstrated that cases of babies born with a birth weight under $1000 \mathrm{~g}$ were more likely to exhibit a psychiatric problem than their normal birth weight counterparts. ${ }^{16}$ However, Doppler status was not formally assessed within the methodology, probably because its routine use predated the starting date of the study.

Limitations of our study include the method of recruitment, which required two rounds of recruitment in order to obtain adequate numbers and led to uneven numbers either side (elevated UAD PI $n=40$, normal UAD PI $n=140$ ), which may have accounted for a skew in the demographic characteristics. Nevertheless, nonresponse was corrected for within the statistical analysis. Correction for confounders was included in multiple

Table 3 Adjusted linear and or logistic regression analysis for elevated (>90th centile) and normal (<90th centile) umbilical artery Doppler (UAD) pulsatility index (PI) for validated British Ability Scales II achievement scale parameters at 28, 34 and 38 weeks, respectively, expressed as mean and SDs

\begin{tabular}{|c|c|c|c|c|c|c|c|c|c|}
\hline \multirow[b]{2}{*}{ Achievement scale } & \multicolumn{3}{|c|}{ Week 28 (1.73 threshold) } & \multicolumn{3}{|c|}{ Week 34 (1.28 threshold) } & \multicolumn{3}{|c|}{ Week 38 (1.17 threshold) } \\
\hline & Normal & Elevated & p Value & Normal & Elevated & p Value & Normal & Elevated & p Value \\
\hline $\begin{array}{l}\text { Number standard } \\
\text { score, mean (SD) }\end{array}$ & $111.6(1.2)$ & $108.1(2.0)$ & 0.143 & $110.8(1.1)$ & $108.5(3.1)$ & 0.484 & $110.1(1.2)$ & $104.9(3.7)$ & 0.188 \\
\hline $\begin{array}{l}\text { Spelling standard } \\
\text { score, mean (SD) }\end{array}$ & $102.5(1.3)$ & $100.1(2.2)$ & 0.340 & $102.0(1.2)$ & $102.2(3.4)$ & 0.947 & $102.0(1.3)$ & $95.6(3.9)$ & 0.124 \\
\hline $\begin{array}{l}\text { Reading standard } \\
\text { score, mean (SD) }\end{array}$ & $98.0(1.2)$ & $98.9(2.0)$ & 0.690 & $98.2(1.1)$ & $99.4(3.3)$ & 0.742 & $98.9(1.2)$ & $95.2(3.7)$ & 0.349 \\
\hline
\end{tabular}




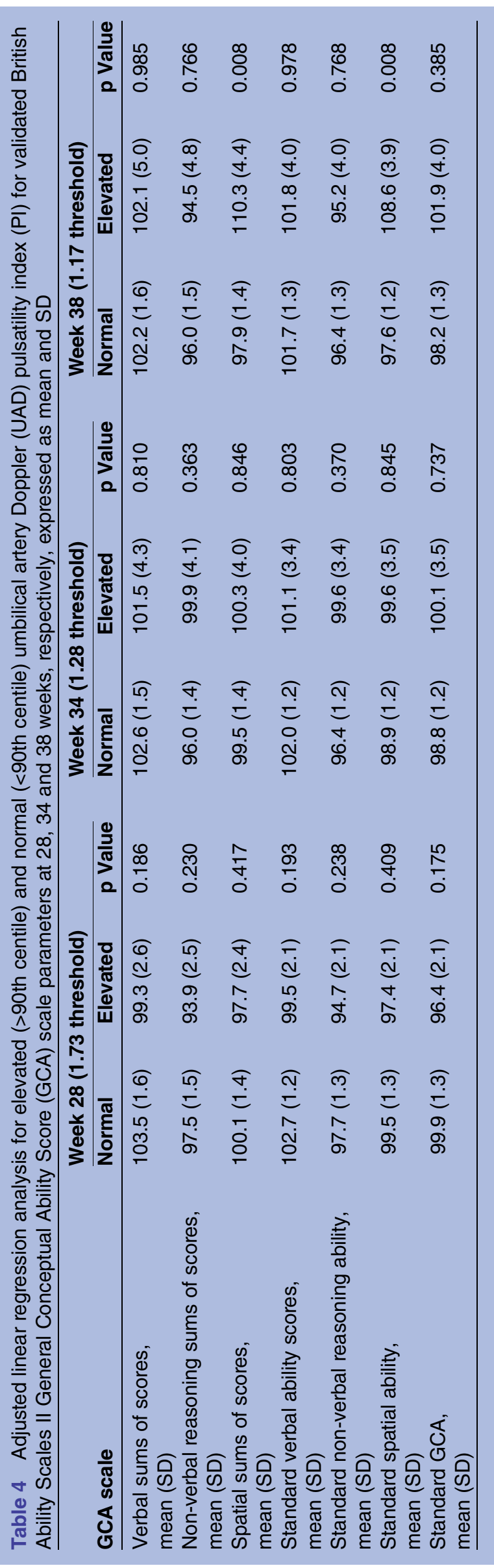

regression. In addition, an attempt to limit bias in the methodology was limited through blinding of the assessors to PI category. One must also note that significant findings were among a large number of outcome measures and hence results must be interpreted with caution.

Interestingly, the findings of this study also add information on the time point where the UAD PI assessment is critical in determining long-term impact on neurodevelopment. Assessments performed at 28 weeks appeared to have the most significant impact on cognitive outcome, notably on information processing and memory. However, this was not the case when UAD PI was assessed at later gestations. It is known that fetuses with FGR are more likely to exhibit long-term cognitive impairment and memory deficit, as has been demonstrated within this study. ${ }^{17}$ The statistically significant results from our study were found in assessments of $\operatorname{cog}$ nitive function focusing on recall of objects verbal and spatial; the area of the brain controlling this function being the hippocampal region which controls declarative memory, with children with elevated UAD PI in utero having poorer scores in these assessments. There were no cases of abnormal development within the study cohort as such cases were excluded at the selection process. What can be extrapolated clinically from this study is that the cohort of patients with an elevated UAD PI were more likely to have lower but not abnormal scores in assessments of short-term and declarative memory function than their normal UAD PI peers, which may express itself as a child having executive-attention deficit and/or mild learning difficulties, somewhat similar to that of children who had FGR in utero. ${ }^{17}$ It is important to note, however, that despite these changes they did not affect the overall academic ability, mental processing and reasoning or overall behavioural function. The latter supports the theory that reduced placental blood flow, notably during the second half of pregnancy, correlates with a reduction in the number of neurons within this area of the fetal brain; as correlated with the histological brains of primates and humans at this stage in addition to vulnerability of hippocampus to injury in the prenatal period. ${ }^{18} 19$ This would certainly go some way to explaining why the earlier abnormal UAD assessment has a stronger association with the abnormal parameters. It is unclear as to why there was no significant difference in parameters at later gestations between groups.

Potential explanations are twofold, primarily as fewer Doppler assessments were performed at these gestations and second, perhaps fetuses at 28 weeks have an altered vulnerability in terms of brain pathophysiology as a result of elevated UAD PI compared to later gestations. ${ }^{10}$ The latter suggestion is supported by existing research which suggests that neurodevelopment is affected by increased impedance in the UAD and aortic indices in early FGR and by cerebral blood flow in late onset IUGR. $^{10}$ 
Table 5 Adjusted linear or logistic regression analysis for elevated (>90th centile) and normal (<90th centile) umbilical artery Doppler (UAD) pulsatility index (PI) for Achenbach child behaviour checklist parent rated version (CBLC) parameters at 28, 34 and 38 weeks, respectively, as expressed as mean with associated SD

\begin{tabular}{|c|c|c|c|c|c|c|c|c|c|}
\hline \multirow[b]{2}{*}{ CBLC parameters } & \multicolumn{3}{|c|}{ Week 28 (1.73 threshold) } & \multicolumn{3}{|c|}{ Week 34 (1.28 threshold) } & \multicolumn{3}{|c|}{ Week 38 (1.17 threshold) } \\
\hline & Normal & Elevated & p Value & Normal & Elevated & p Value & Normal & Elevated & p Value \\
\hline $\begin{array}{l}\text { CBLC withdrawn, }{ }^{*} \\
\text { mean (SD) }\end{array}$ & $0.40(0.05)$ & $0.38(0.08)$ & 0.889 & $0.40(0.04)$ & $0.36(0.13)$ & 0.770 & $0.41(0.05)$ & $0.27(0.13)$ & 0.310 \\
\hline $\begin{array}{l}\text { CBLC somatic problems, }{ }^{*} \\
\text { mean (SD) }\end{array}$ & $0.53(0.05)$ & $0.66(0.08)$ & 0.150 & $0.58(0.04)$ & $0.33(0.12)$ & 0.056 & $0.60(0.05)$ & $0.40(0.14)$ & 0.165 \\
\hline $\begin{array}{l}\text { CBLC anxious/depressed, }{ }^{*} \\
\text { mean (SD) }\end{array}$ & $0.52(0.05)$ & $0.59(0.08)$ & 0.444 & $0.54(0.04)$ & $0.43(0.13)$ & 0.412 & $0.53(0.05)$ & $0.63(0.13)$ & 0.506 \\
\hline $\begin{array}{l}\text { CBLC social problems, }{ }^{*} \\
\text { mean (SD) }\end{array}$ & $0.52(0.05)$ & $0.54(0.08)$ & 0.803 & $0.52(0.04)$ & $0.39(0.12)$ & 0.317 & $0.50(0.05)$ & $0.40(0.14)$ & 0.484 \\
\hline $\begin{array}{l}\text { CBLC thought/behaviour, } \\
\text { mean (SD) }\end{array}$ & $0.57(0.05)$ & $0.57(0.08)$ & 0.930 & $0.59(0.04)$ & $0.34(0.11)$ & 0.063 & $0.56(0.05)$ & $0.49(0.14)$ & 0.659 \\
\hline $\begin{array}{l}\text { CBLC attention problems, } \\
\text { mean (SD) }\end{array}$ & $0.50(0.05)$ & $0.58(0.09)$ & 0.466 & $0.54(0.05)$ & $0.34(0.13)$ & 0.169 & $0.56(0.05)$ & $0.26(0.12)$ & 0.056 \\
\hline $\begin{array}{l}\text { CBLC delinquent behaviour, } \\
\text { mean (SD) }\end{array}$ & $0.70(0.05)$ & $0.88(0.05)$ & 0.021 & $0.76(0.04)$ & $0.57(0.14)$ & 0.139 & $0.73(0.05)$ & $0.75(0.13)$ & 0.884 \\
\hline $\begin{array}{l}\text { CBLC aggressive behaviour, } \\
\text { mean (SD) }\end{array}$ & $0.49(0.05)$ & $0.56(0.08)$ & 0.517 & $0.49(0.05)$ & $0.41(0.14)$ & 0.597 & $0.46(0.05)$ & $0.66(0.15)$ & 0.179 \\
\hline $\begin{array}{l}\text { CBLC other problems, }{ }^{*} \\
\text { mean (SD) }\end{array}$ & $0.52(0.05)$ & $0.64(0.08)$ & 0.215 & $0.55(0.04)$ & $0.44(0.13)$ & 0.404 & $0.54(0.05)$ & $0.48(0.15)$ & 0.683 \\
\hline $\begin{array}{l}\text { CBLC internalising, }{ }^{*} \\
\text { mean (SD) }\end{array}$ & $0.52(0.05)$ & $0.64(0.08)$ & 0.193 & $0.56(0.04)$ & $0.45(0.13)$ & 0.399 & $0.57(0.05)$ & $0.57(0.14)$ & 0.983 \\
\hline $\begin{array}{l}\text { CBLC externalising, }{ }^{*} \\
\text { mean (SD) }\end{array}$ & $0.49(0.05)$ & $0.57(0.08)$ & 0.412 & $0.50(0.05)$ & $0.41(0.14)$ & 0.566 & $0.47(0.05)$ & $0.66(0.15)$ & 0.207 \\
\hline $\begin{array}{l}\text { CBLC internalising standard score, } \\
\text { mean (SD) }\end{array}$ & $52.0(0.9)$ & $51.4(1.5)$ & 0.759 & $51.7(0.8)$ & $54.2(2.5)$ & 0.331 & $51.7(1.0)$ & $53.6(2.8)$ & 0.523 \\
\hline $\begin{array}{l}\text { CBLC externalising standard score, } \\
\text { mean (SD) }\end{array}$ & $49.8(0.9)$ & $48.0(1.5)$ & 0.290 & $49.4(0.8)$ & 53.7 (2.3) & 0.079 & $50.2(0.9)$ & $50.7(2.7)$ & 0.860 \\
\hline CBLC total standard score, mean (SD) & $45.2(0.8)$ & $44.0(1.4)$ & 0.464 & $44.8(0.8)$ & $49.0(2.2)$ & 0.074 & $45.3(0.9)$ & $46.6(2.5)$ & 0.642 \\
\hline
\end{tabular}


It is a challenge to determine the clinical implications of this study as one refers to a test which is not indicated for the general unselected pregnant population. Certainly, if the definition of FGR was revised and the fetuses with elevated UAD PI were truly growth restricted and all of their placentae were retrospectively histopathologically examined, then perhaps this would support re-exploring the definition of FGR. Additionally, due to the demonstrated apparent deficit in short-term memory at childhood follow-up, a focus should be made on those children who had FGR to facilitate orientation, and direct attention and reiteration of material to optimise learning performance. ${ }^{17}$

\section{CONCLUSION}

An elevated UAD PI at 28 weeks' gestation in the absence of FGR or prematurity is associated with some adverse cognitive findings in children aged 12 years. A potential explanation for this phenomenon is an element of placental insufficiency in the presence of the appropriately grown fetus which affects the development of the fetal hippocampus, and this information processing and memory long-term further studies should be performed before firm conclusions or guidance can be drawn from the findings of this study.

\section{Author affiliations}

${ }^{1}$ UCD Obstetrics and Gynaecology, School of Medicine and Medical Science, University College Dublin, National Maternity Hospital, Dublin, Ireland 2Department of Fetal Medicine, National Maternity Hospital, Dublin, Ireland ${ }^{3}$ Department of Early Childhood Studies, Stranmillis University College, Belfast, UK

${ }^{4}$ Royal Belfast Hospital for Sick Children, Belfast Health \& Social Care Trust, Belfast, UK

${ }^{5}$ CSTAR, School of Public Health, Physiotherapy and Population Science, University College Dublin, Dublin, Ireland

${ }^{6}$ Department of Psychology, Queen's University Belfast, Belfast, UK ${ }^{7}$ Department of Fetal Medicine, Royal Maternity Hospital, Belfast, UK ${ }^{8}$ Centre for Infection \& Immunity, Queen's University Belfast, Belfast, UK

Acknowledgements Dr Eoghan Mooney, consultant pathologist, Department of Pathology and Laboratory Medicine, National Maternity Hospital, Holles St, Dublin, Ireland for contribution to construction of manuscript and theory.

Contributors FM analysed and interpreted the data, drafted, reviewed and revised the manuscript and approved the final version as submitted. BMcC and AT conceptualised and designed the study, acquired the data, carried out the initial analysis and revised the article critically for intellectual content and approved the final manuscript as submitted. RS, SO and FMMcA performed the final analysis and interpretation of the data, revised the article critically for intellectual content and approved the final manuscript as submitted. PH, MCS, JCD and MDS conceptualised and designed the study and data collection instruments, and coordinated and supervised data collection in addition to critically reviewing the manuscript and approving the final manuscript as submitted.

Funding All phases of this study were funded by the Department of Health and Social Care, Northern Ireland, UK and TinyLife (formerly NIMBA), UK.
Competing interests None declared.

Ethics approval Northern Ireland Research and Ethics Committee, Queen's University Belfast, Northern Ireland, UK.

Provenance and peer review Not commissioned; externally peer reviewed.

Data sharing statement Further data from this study include data on childhood respiratory function testing which is currently being analysed and will be published as a separate manuscript in due course.

Open Access This is an Open Access article distributed in accordance with the Creative Commons Attribution Non Commercial (CC BY-NC 4.0) license, which permits others to distribute, remix, adapt, build upon this work noncommercially, and license their derivative works on different terms, provided the original work is properly cited and the use is non-commercial. See: http:// creativecommons.org/licenses/by-nc/4.0/

\section{REFERENCES}

1. de Boo HA, Harding JE. The developmental origins of adult disease (Barker) hypothesis. Aust N Z J Obstet Gynaecol 2006;46:4-14.

2. Pinney SE. Intrauterine growth retardation-a developmental model of type 2 diabetes. Drug Discov Today Dis Models 2013;10:71-7.

3. Mu M, Ye S, Bai MJ, et al. Birth weight and subsequent risk of asthma: a systematic review and meta-analysis. Heart Lung Circ 2014;23:511-19.

4. Mone F, Thompson A, Stewart M, et al. Fetal umbilical artery Doppler pulsatility index as a predictor of cardiovascular risk factors in children-a long-term follow up study. J Matern Fetal Neonatal Med 2014;27:1633-6.

5. Mone F, McAuliffe FM, Ong S. The clinical application of Doppler ultrasound in obstetrics. Obstetrician Gynaecologist 2015;17:13-19.

6. Alfirevic Z, Stampalija T, Gyte JM. Fetal and umbilical Doppler ultrasound in normal pregnancy. Cochrane Database Syst Rev 2010; (8):CD001450.

7. Levine TA, Grunau RE, McAuliffe FM, et al. Early Childhood neurodevelopment after intrauterine growth restriction: a systematic review. Pediatrics 2015;135:126-41.

8. Fogarty $\mathrm{P}$, Beattie B, Harper A, et al. Continuous wave Doppler flow velocity waveforms from the umbilical artery in normal pregnancy. $J$ Perinat Med 1990;18;51-7.

9. Beattie RB, Dornan JC. Antenatal screening for intrauterine growth retardation with umbilical artery Doppler ultrasonography. BMJ 1989;298:631-5.

10. Baschat AA. Neurodevelopment following fetal growth restriction and its relationship with antepartum parameters of placental dysfunction. Ultrasound Obstet Gynecol 2011;37:501-4.

11. Elliott CD, Smith P, Mcculloch P, eds. Bas II technical manual. London; NFER-Nelson Windsor, 1997.

12. Achenbach TM, ed. Manual for the Child Behaviour checklist and revised child behaviour profile. Burlington: Queen city printers, 1991.

13. Baschat AA. Fetal Growth restriction-from observation to intervention. J Perinat Med 2010;38:239-46.

14. Wienerroither $\mathrm{H}$, Steiner $\mathrm{H}$, Tomaselli $\mathrm{J}$, et al. Intrauterine blood flow and long-term intellectual, neurologic, and social development. Obstetr Gynecol 2001;97:449-53.

15. Morales-Roselló J, Khalil A, Papageorghiou A, et al. Changes in fetal Doppler indices as a marker of failure to reach growth potential at term. Ultrasound Obstet Gynaecol 2014;43:303-10.

16. Van Lieshout RJ, Boyle MH, Saigal S, et al. Mental health of extremely low birth weight survivors in their 30 s. Pediatrics 2015;135:452-9.

17. Geva R, Eshel R, Leitner $\mathrm{Y}$, et al. Memory functions of children born with asymmetric intrauterine growth restriction. Brain Res 2006;1117:186-94.

18. Isaacs EB, Vargha-Khadem F, Watkins KE, et al. Developmental amnesia and its relationship to degree of hippocampal atrophy. Proc Natl Acad Sci USA 2003;28:13060-3.

19. Hevner RF, Kinney HC. Reciprocal enthorhinal-hippocampal connections established by human fetal midgestation. J Comp Neurol 1996;372:384-94. 